\title{
Impact of Dynamic Light and Nutrient Environments on Phytoplankton Communities in the Coastal Ocean
}

\author{
Mark A. Moline, Oscar Schofield and Joe Grzymski
}

When we try to pick out anything by itself, we find it hitched to everything else in the Universe.

John Muir $(1838-1914\}$

\section{In this chapter you will be able to explore:}

- Responses of phytoplankton growth to light fields and nutrient concentrations;

- Effects of eutrophication on the siructure of phytoplankton communities.

\subsection{Introduction}

Phytoplankton represent the base of the food web in marine ecosystems. Changes in the structure and composition of these phytoplankton communities will, therefore, have a direct effect on the amount of carbon available to higher trophic levels. In the absence of significant grazing, light and nutrients are the primary factors regulating phytoplankton photosynthesis and productivity in marine environments. As the requirements for light and nutrients differ between species, phytoplankton community structure is also sensitive to dynamic optical and chemical conditions in the water column.

Nutrient loading in coastal regions from agriculiural runoff and urbanization has been documented on a global scale. Nitrogen $(\mathrm{N})$ and phosphorous (P) inputs into coastal seas have increased four-fold, leading to considerable eutrophication (Martin et al. 1981; Nixon 1995). These nutrient additions result in significant shifts in the ratios of macronutrients in the coastal margins. Shifts in nuirient ratios can alter phytoplankion community structure, changing the timing and abundance of dominant phytoplankton species in coastal areas (Sommer 1989; Admiraal et al. 1990; Smayda 1990; Officer and Ryther 1980; Conley et al. 1993; Turner and Rabalais 1994). Increases in $\mathrm{N}$ and $\mathrm{P}$ concentrations relative to silicate $(\mathrm{Si})$ concentrations have been shown to favor the dominance of non-siliceous phytoplankton over siliceous di- 
atom species (Humborg et al. 1997). These non-siliceous phytoplankton are predominantly flagellates, often dinoflagellates, forming dense blooms along the coast. The occurrence of these blooms has raised concern as they are increasing in frequency and are often toxic (see Anderson and Garrison 1997). These toxic blooms are associated with massive mortalities in fish (both farmed and wild), shellfish, birds, and marine mammals. Although there are no global estimates of economic losses due to harnful algal blooms, estimates from isolated individual events provide some indication of the scale of the problem. In Alaska alone, it is estimated that losses from the shellfish industry are $\$ 50$ million annually (Neve and Reichardt 1984). The Gulf coast of Florida experiences frequent red tides, often accompanied by dead fish washing up on beaches, contaminated shellfish, and human respiratory problems owing to toxics aerosolized by the surf. Habas and Gilbert (1974) estimated a loss of $\$ 20$ million for each event in 1974 .

Increased sediment loading and changing bloom composition also modify the relative light fields to which phytoplankton are exposed. As with nutrients, different phytoplankton groups and species respond differently to light intensity with respect to photosynthesis and growth. This exerts an additional selective mechanism on the phytoplankton community structure that may influence the coastal food web. Recent significant changes in environmental conditions select against species that have narrow tolerance ranges with respect to nutrients and light.

\subsection{Model Formulation}

Here we demonstrate the dynamics and multiple feedback mechanisms between phytoplankton abundance, light and nutrients. The model integrates the concepts of nutrient uptake kinetics, light utilization and photosynthesis with respect to changing envirommental conditions. Given these interactions, the impacts of changing nutrient ratios, the effects of water column mixing and light propagation on phytoplankton abundance and community structure can be predicted. The model is designed to help elucidate some potential anthropogenic impacts on phytoplankton communities in coastal ocean environments.

\subsubsection{Physical Environment}

The pliysical portion of the model follows a $1 \mathrm{~m}^{3}$ parcel of water (Lagrangian) in one cimension (vertical) over time. Following a single parcel of water is appropriate because the objective of the model is to examine a large-scale phenomenon, where it is assumed that similar processes are occurring in adjacent water masses. This parcel of water is then mixed, expressed as a simplified description of circular motion, which leads to a sinshaped variation of the depth $(Z)$ similar to Pahl- Wostl (1992). 
Both the Mixed Layer Depth and the Length of Rotation Period can be vatried with time to reflect different mixing regimes. The Length of Rotation Period must be an integer in the model as it is relative to Julian date (TTME). The module of Figure 8.1 captures the calculations of Mixed Layer Depth, Length of Rotation Period, and $Z(t)$.

\subsubsection{In Situ Light Field}

The light field impinging on the parcel of water at any given time is specified as a function of the incident light field at the surface, the depth of the parcel of water and the attenuation of light through the water column. The surface incident light field at a given time over the year $(I O(t))$ is quantified as a cubic sin function according Marra (1978):

$$
\left.\operatorname{Io}(t)=\max \operatorname{SIN}\left(P I^{*} T H M E / 365\right)^{3}\right)+(\operatorname{Imin}),
$$

where $\operatorname{Imax}$ is the maximum irradiance (moles photons $/ \mathrm{m}^{2} / \mathrm{d}$ ). Imin sets a minimum value during the winter solstice. The value of 2 moles photons $/ \mathrm{m}^{2} / \mathrm{d}$ is used as an estimate for the Baltic Sea, where the effect of nutrient runoff on phytoplankton communities has been shown and where this model will be demonstrated (Conley et al. 1993). The in situ light field affecting the parcel of water $(I z)$ is therefore a fraction of Equation 2 ,

$$
I \approx(t)=I O(t)^{*} E X P(-1 * A T T * Z)
$$

where light attenuates exponentially with depth and where $A T T$ is the attenuation coefficient (Kirk 1994). The attenuation coefficient is a function of the attenuation owing to water and dissolved material $(0.3$ is used as an

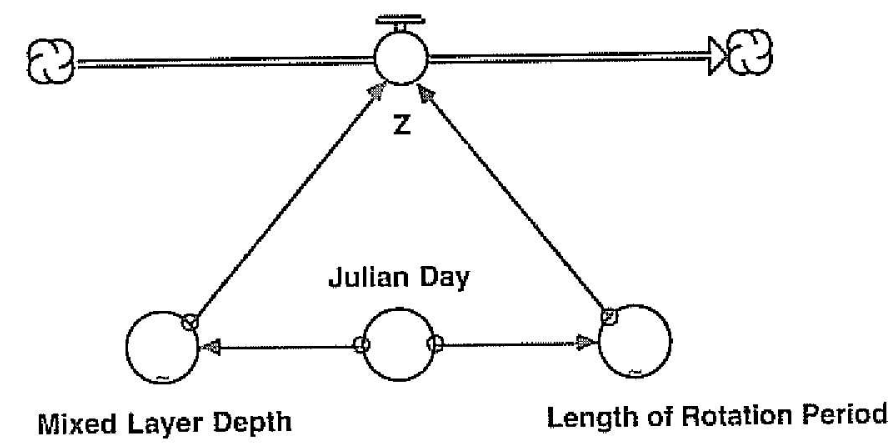

Figure 8.1 


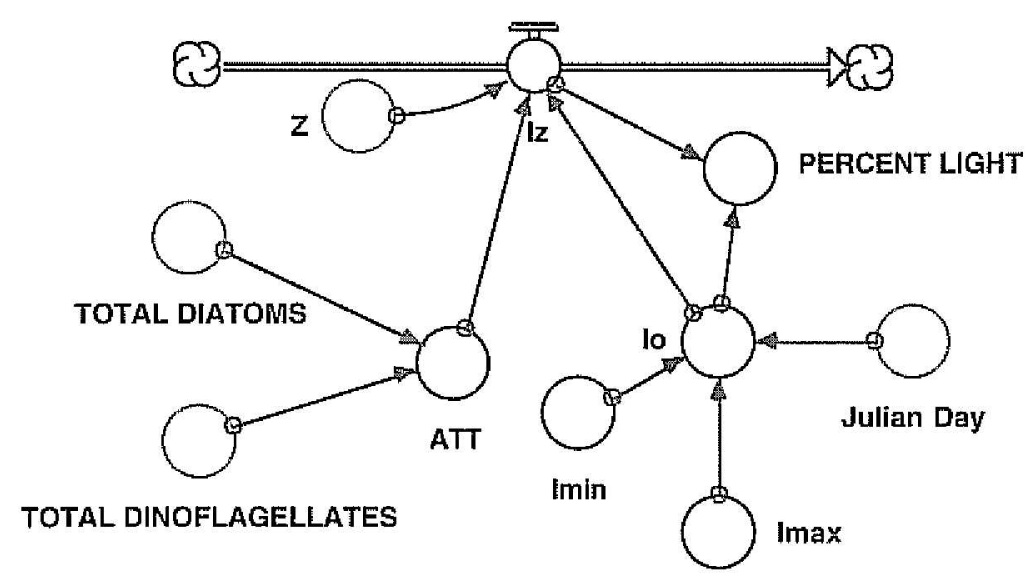

FIGURE 8.2

average value; Kirk 1994) and the attenuation owing to the accumulation of phytoplankton cells, creating a dynamic feedback over time (Figure 8.2).

\subsubsection{Phytoplankton Groups}

Two phytoplankton groups are used in this model to illustrate the competitive interaction resulting from nutrient loading in coastal regions. Diatoms are historically the dominant bloom-forming phytoplankton, responsible for the majority of the biomass reaching higher trophic levels. Dinofiagellates are flagellated single-celled algae that have more recently been found to form significant, and occasionally toxic, bloons.

Phytoplankton from both groups are able to respond differentially to light according to the photosynthesis-irradiance relationship given by the hyperbolic tangent model of Neale and Richerson (1987), such that

$$
\text { Pbytoplankton Grototb = Growth Nutrient *TANH }(I z / I k) \text {, }
$$

where either the diatom or dinoflagellate growth rate is a fraction of the maximum growth rate, scaled to the nutrient-dependent growth rate (see Figure 8.3 and 8.4 , and below).

The fraction of the maximum growth rate is dependent on the ratio of the in situ light level, specified in equation (3), and $l k$, the irradiance level at which photosynthesis (and growth) is saturated. The hyperbolic tangent (TANH) is not a built-in function of STELLA and therefore requires trigonometric formulation. The final growth rate is used to calculate the number of new cells per DT ( 1 day), based on the number of cells in the previous time step. In order to maintain cells beyond a single time step, cells in the model 


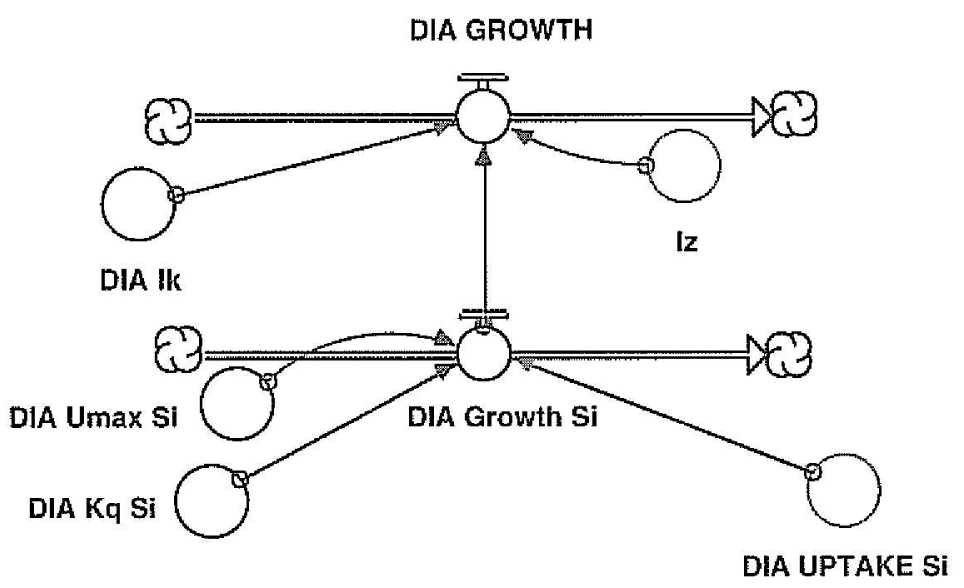

FIGURE 8.3

are sequentially "moved" to conveyors (Figures 8.5 and 8.6). For this model, the lifetime of a cell is 4 days. A minimum population of 50 cells $/ \mathrm{m}^{3}$ is maintained for each group.

\subsubsection{Nutrient Concentrations and Nutrient Requirements}

Nutrient concentrations for both $\mathrm{Si}$ and $\mathrm{N}$ are expressed as the number of moles in the cubic-meter parcel of water. The loss of nutrients over time is a function of the uptake rate per phytoplankton cell and the total number

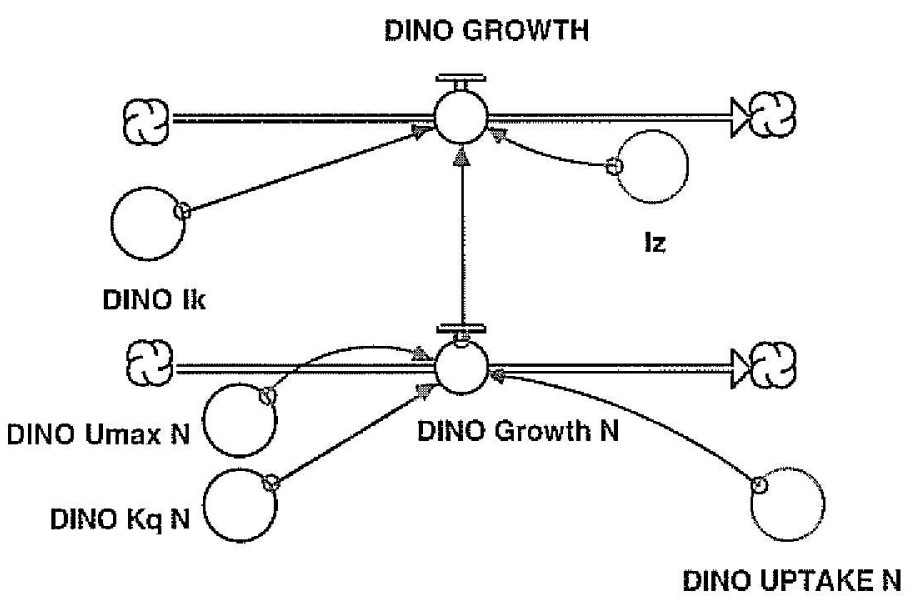

FIGURE 8.4 


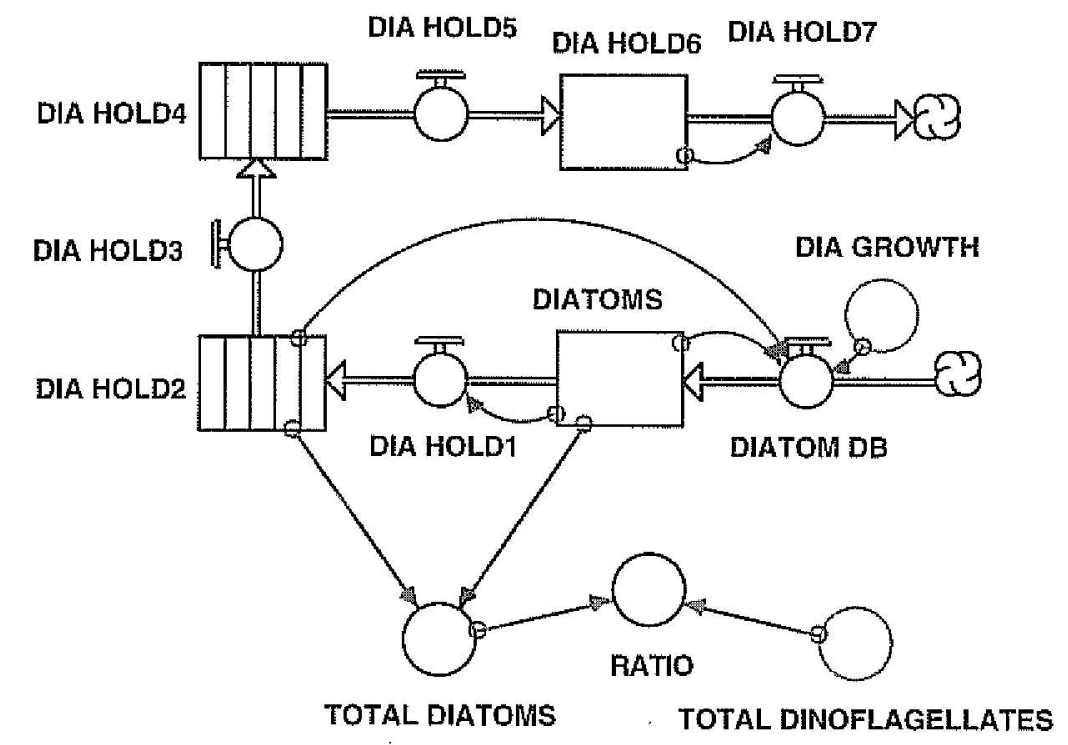

FIGURE 8.5

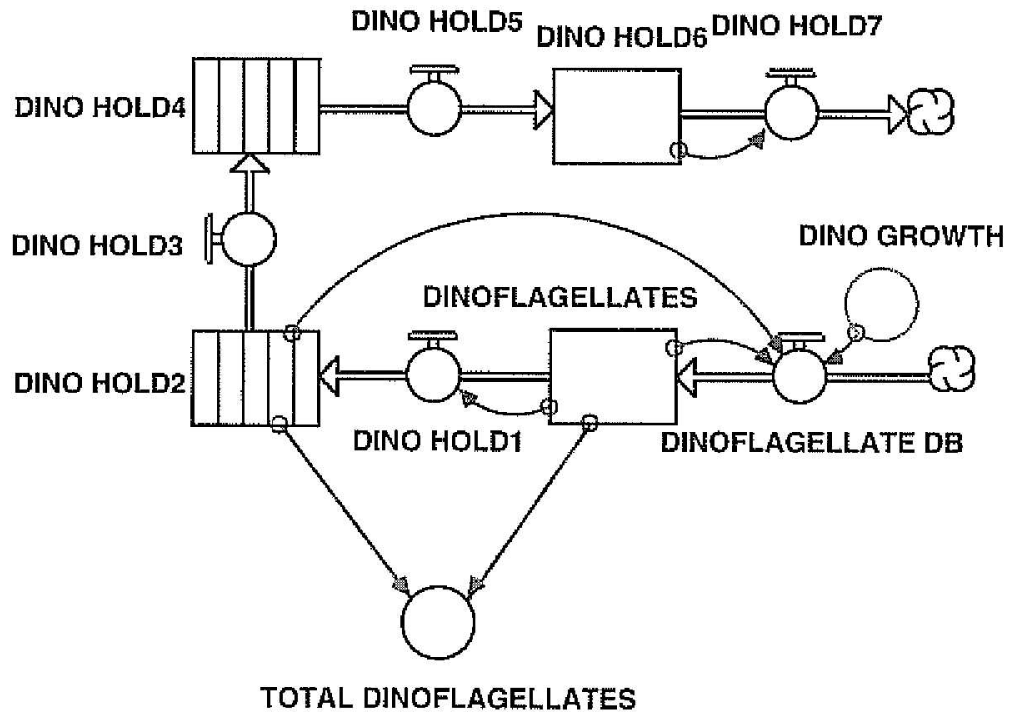

FICURE 8.6 
of cells utilizing the nutrient. In the case of $\mathrm{N}$, both dinoflagellate and diatom abundance influences the uptake rate. The uptake rate of nutrients are also a function of the light level, where the maximum uptake for both $\mathrm{N}$ and Si occurs when light levels are greater than $20 \%$ surface irradiance (Dugdale et al. 1981). The uptake of each group of each nutrient (Group_Uptake_Nutrient) follows Michaelis-Menton kinetics, such that

Uplake Nutrient $=V_{\text {max }}$ Nutrient ${ }^{*}($ Nutrient/ $($ Nutrient $)+K s$ Nutrient $\left.)\right), \quad($

where Vmax is the maximum uptake rate per cell of a given nutrient and $K S$ is the half-saturation constant (the nutrient concentration [Nutrient] supporting half $V_{m}(x)$. Becalse diatoms require both $\mathrm{N}$ and $\mathrm{Si}$, the maximum uptake of Si by diatoms was scaled to the diatom uptake of nitrogen. The dissolved nutrients (within the parcel of water) are taken up by phytoplanliton cells, and there is a length of time before the nutrients are regenerated and returned to the dissolved form. The regeneration time for $\mathrm{N}$ is assumed to be shorter than that for Si because regeneration of $\mathrm{N}$ is biologically mediated (Officer and Ryther 1980).

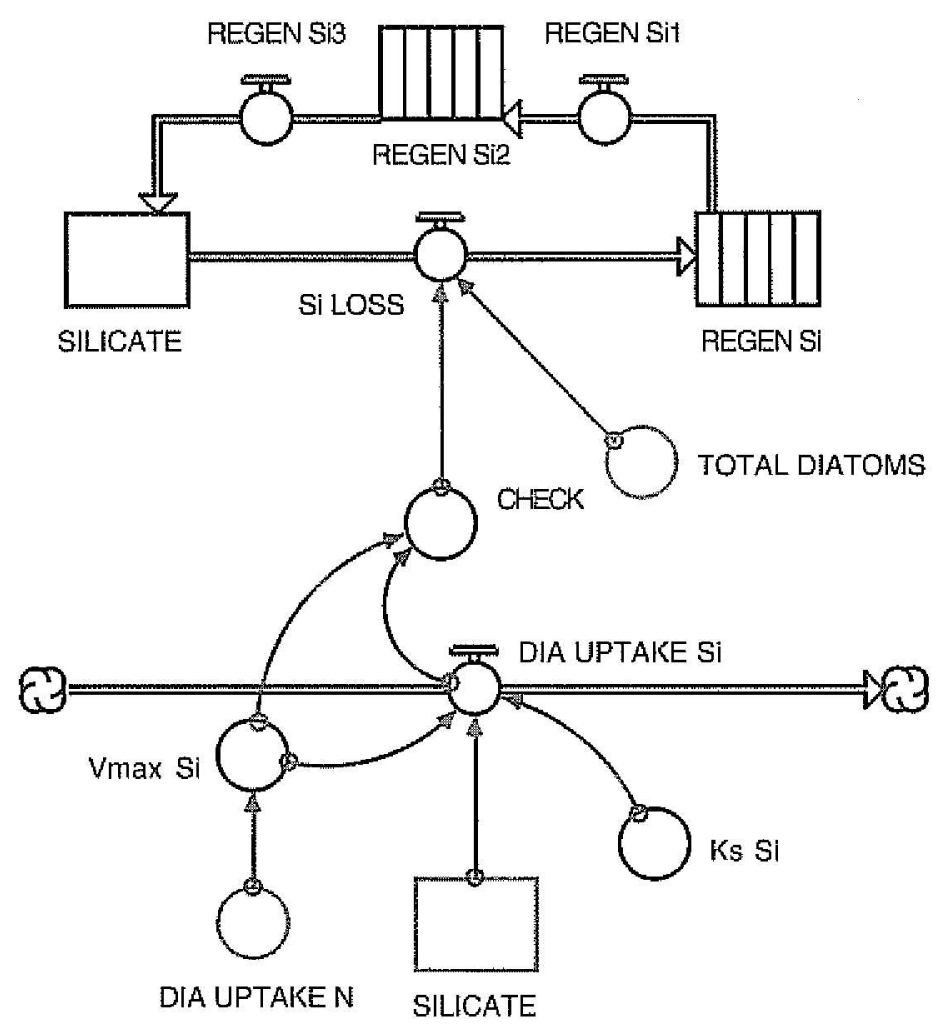

FIGURE 8.7 
The maximum growth rate for either species is dependent on the nutrient conditions within the cells. Since dinoflagellates do not require $\mathrm{Si}$, the maximum growth rate for dinoflagellates is dependent on the availability of $\mathrm{N}$. For diatoms, the model is formulated to account for limitation by both $\mathrm{Si}$ and $\mathrm{N}$. The result is a competition for $\mathrm{N}$ governed by the availability of Si. The nutrients taken up by each phytoplankton cell are considered the nutrients within each cell or the cell quota. The growth rate of each phytoplankton group (Grouth Nutrient) is based on the cell quota according to Droop (1967),

$$
\text { Growth Nutrient }=\text { Growth }_{\text {mux }} \text { Nutrient } *(1-\mathrm{Kq} / \mathrm{Q})
$$

where Growtb ${ }_{\text {max }}$ Nutrien is the maximum growth rate, $K q$ is the subsistence quota for zero growth per cell and $Q$ is the cell quota of the nutrient.

The calculation of changes in nutrient concentrations are carried out in the modules of Figures 8.7 and 8.8 .

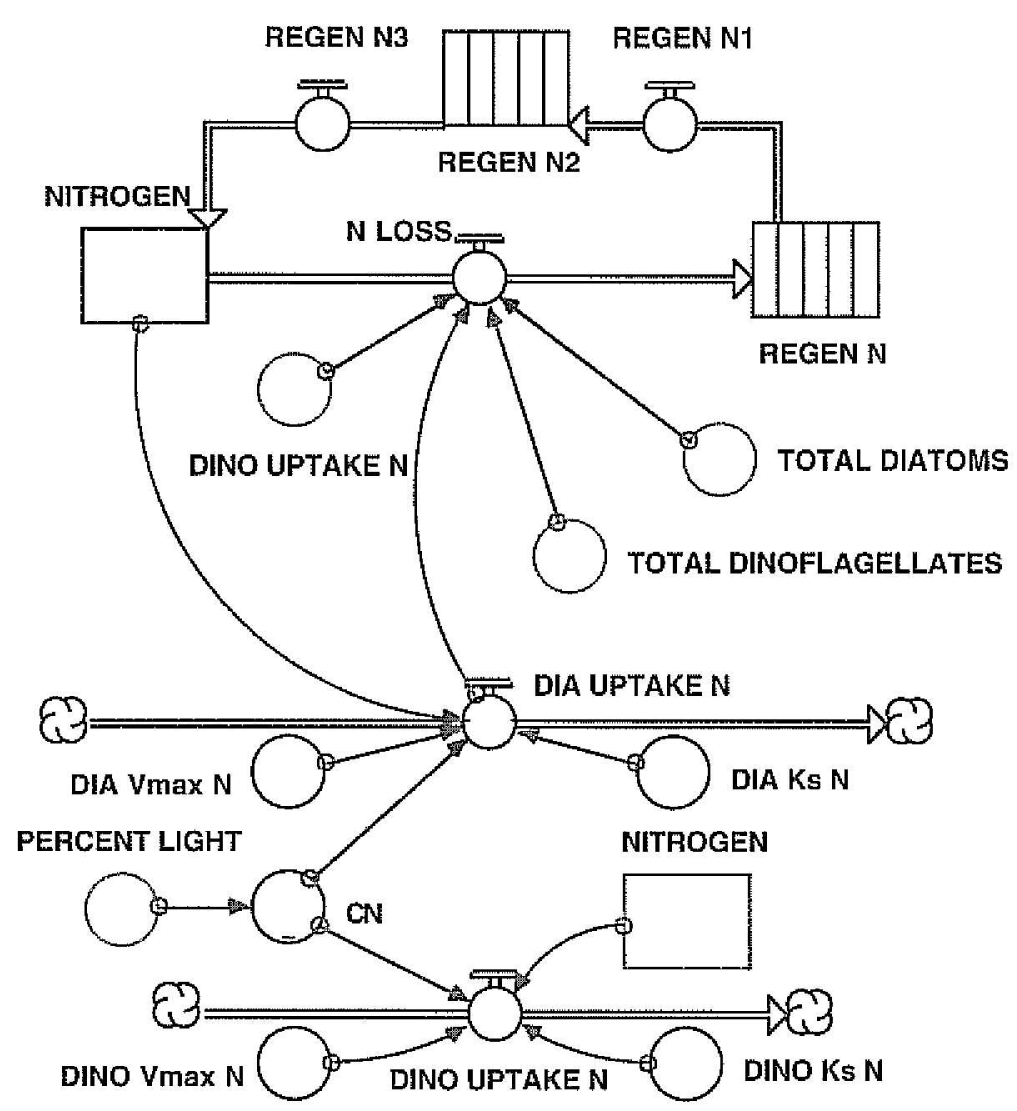

FIGURE 8.8 


\subsection{Model Results}

The results discussed in this section have been derived under a set of simplifying assumptions. Specifically, the present model examines dynamics with two phytoplankton groups. As with any marine environment, there are more than two phytoplankton groups, and within groups, phytoplankton species have significantly different responses to both light and nutrients. Phytoplankton in the natural environment are always subject to grazing pressure from zooplankton. Inclusion of grazing in this model would add another cynamic variable affecting the number of phytoplankton cells and increasing the regeneration time of $\mathrm{N}$. The addition of more than two nutrients would add further realism to the model.

\subsubsection{Physical Dynamics}

In order to illustrate the physical dynamics in the model, let us follow total diatoms and dinoflagellate populations over the course of two years. In this case, the effects of light and nutrients are equal for both phytoplankton groups. To generate equal nutrient requirements for both groups, the $K s$ value for $\mathrm{Si}$ is set to 0 so that $\mathrm{N}$ is the only nutrient being equally utilized by both groups. The dynamics shown in Figure 8.9 are a function of variable mixing depth, period of rotation of the parcel of water and the annual change in the incident solar radiation. Differences between years illustrate the variable use of the $\mathrm{N}$ pool over the year and the feedback of increasing cell numbers, increased attenuation and decreasing light available for growth.

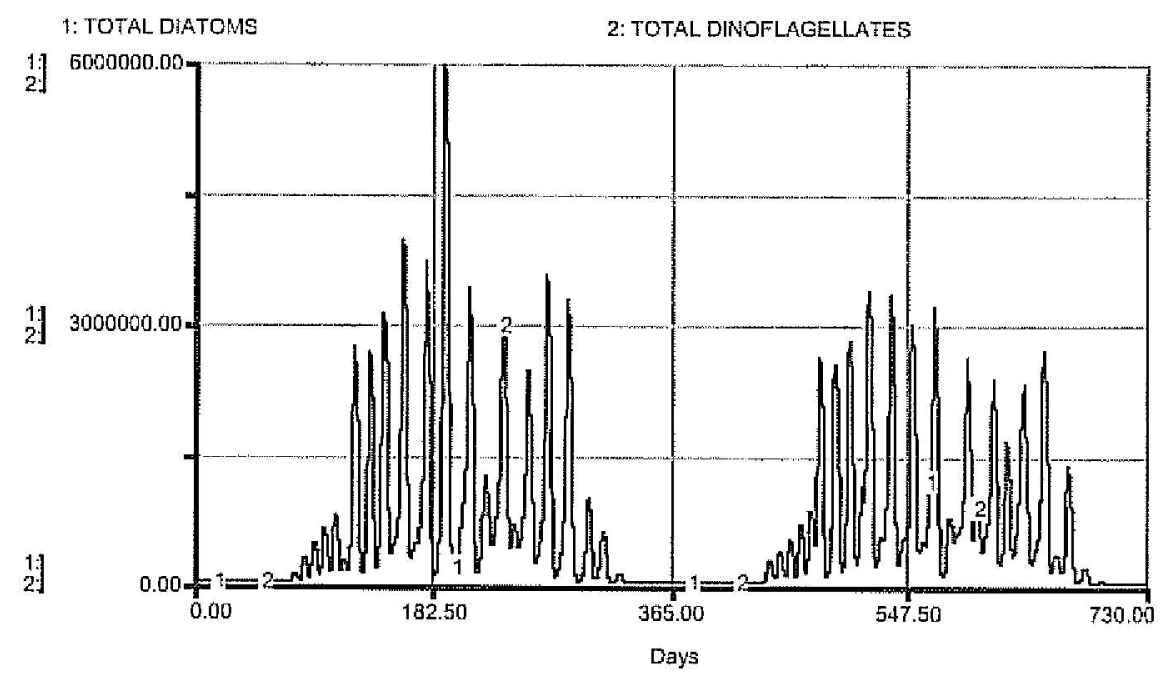

FiGURE 8.9 


\subsubsection{Light and Growth}

In configuring the model to a constant mixing depth (20 meters), and no mixing over the solin cycle each year, the model runs illustrate the impact of light and nutrients on the two phytoplankton populations. In general, diatoms in the coastal oceans show higher maximum growth rates than other plytoplankton groups. If the maximum growth rate in the model is in creased from 1.0 to 1.2 (maximum dinoflagellate growth rate is set to 1.0 ), the model output shows significantly higher diatom populations over time (Figure 8.10). Although the dinofligellates show a rapid increase at the beginning of each year, about one month into each year numbers decrease because of the lack of light from the high attenuation of the large diatom population.

With the growth rates of both phytoplanliton groups equal, the ability of the cells to compete for light can be examined. $I k$ is the minimum light level at which maximum photosynthesis (and growth) can be achieved. The lower the value for $I k$, the lower the light needed to saturate maximum growth. Species in both phytoplankton groups have been shown to have low $l k$ values. For example, ice algae (both diatoms and dinoflagellates) are embedded in surface ice over the winter and are exposed to extremely low incident light. Figure 8.11 shows the case in which the diatom $I k$ is set to 3.2 moles photons $/ \mathrm{m}^{2} / \mathrm{d}$ and dinoflagellates have lower $I k$ ( 2.5 moles photons $/ \mathrm{m}^{2} / \mathrm{d}$ ). In his case, dinoflagellates easily dominate over diatoms, with similar light limitation dynamics as in Figure 8.10.

By altering both the maximum growth rates and the $I k$ values simultaneously in the model, the interactions between the variables can be elucidated.

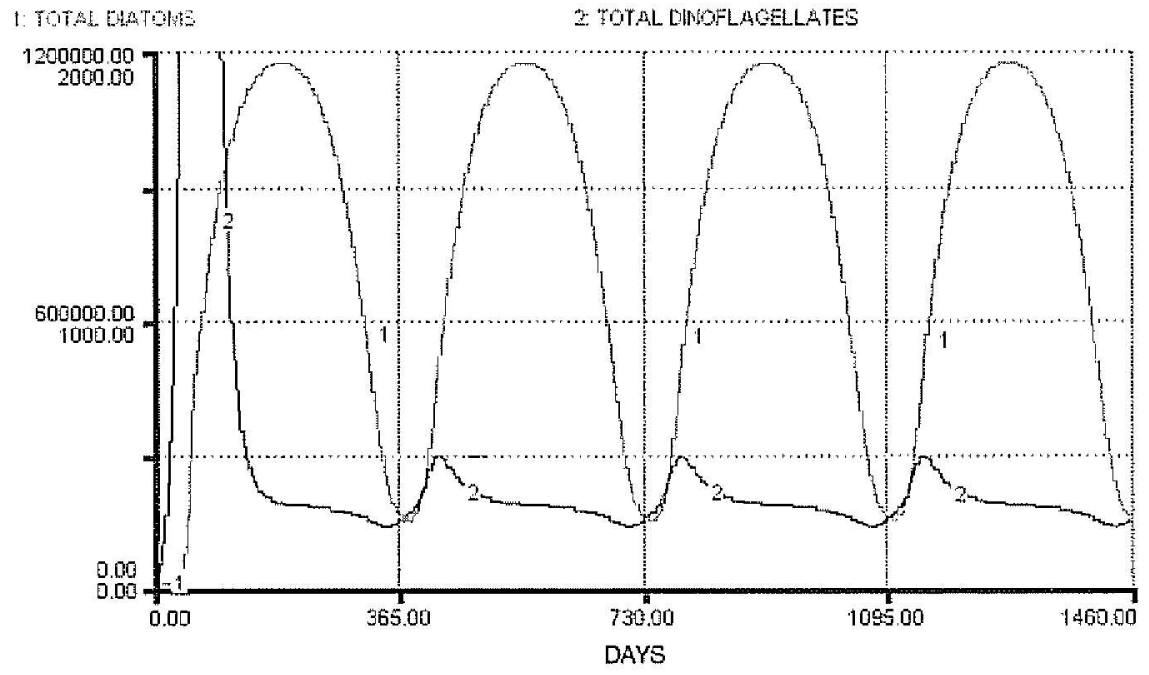

FIGURE 8.10 


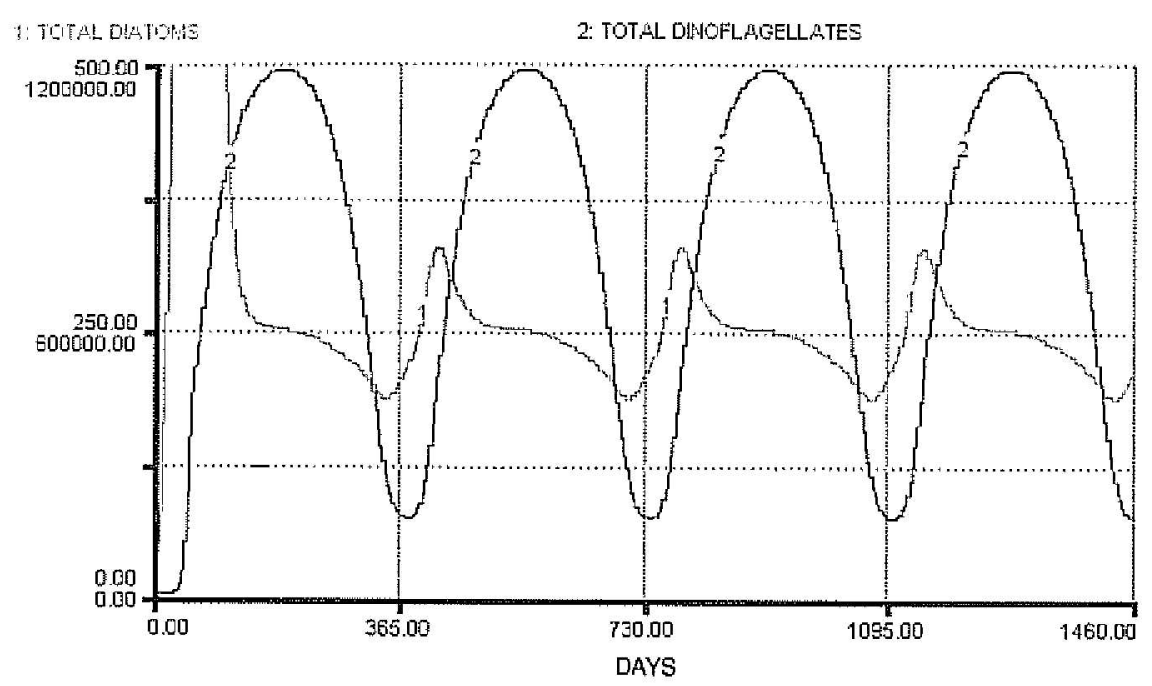

FIGURE 8.11

For example, set $I k$ values to those in Figure 8.11, the maximum growth rate for diatoms to 1.26 and leave the maximum dinoflagellate growth at 1.0. Run the model for four years to see both inter- and intra-annual dynamics (Figure 8.12). Despite a higher growth rate, diatom abundance is now not so high as that for dinoflagellates. The ability of clinoflagellate cells to better compete for light allows them to peak earlier than diatom cells. The higher

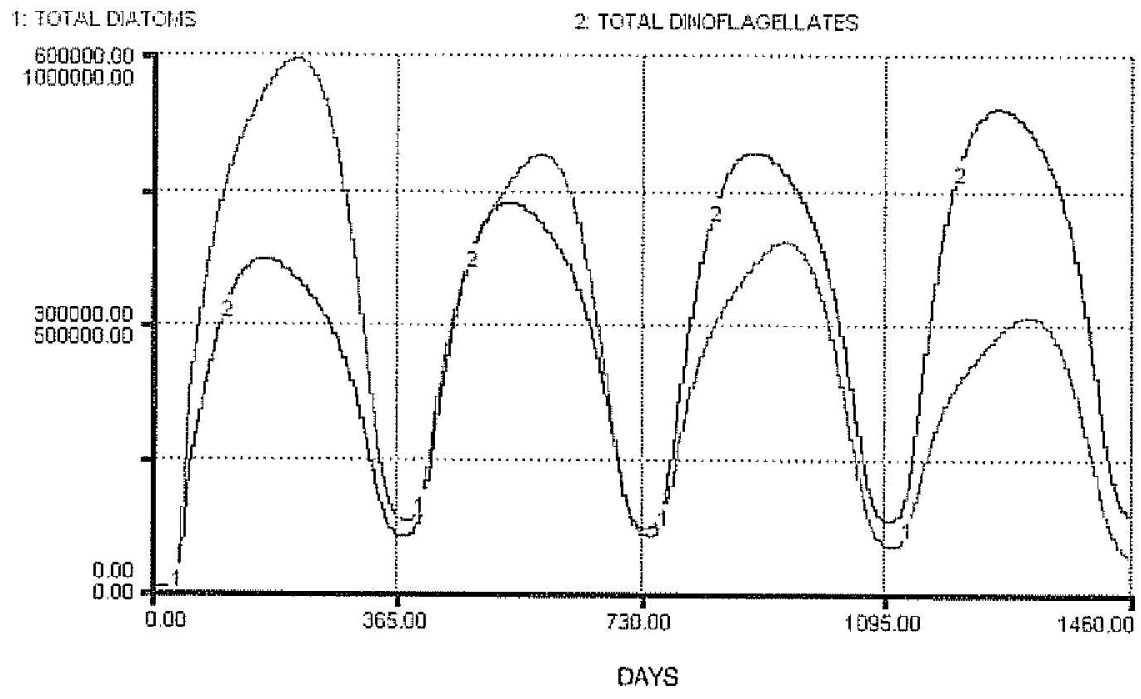

FIGURE 8.12 
growth rate for diatoms, however, prevents the light limited decline shown in Figures 8.10 and 8.11. Dinoflagellates increase with each successive season because of a higher initial seed population at the beginning of each year, while diatoms show the opposite trend. Interestingly, if the light level is decreased under these conditions (mixing clepth increased), the intensity of the interannual trend decreases.

\subsubsection{Nutrient Dynamics}

Let us next examine the impact of nutrients on phytoplankton communities. To do so, we assume there are no mixing dynamics and that growth and responses to light are equal for diatoms and dinoflagellates. We also assume that both phytoplankton groups are equally dependent on the lation first condition ( $N$ at 0.003 concentrations can be seen. Over the two years, the ing to changes in the incident $\mathrm{m}^{3}$ ) shows the population simply respondThe second run assumes a starting irradiance over the year (Figure 8.13). temporary increases in population value of $N=0.0004$ moles $/ \mathrm{m}^{3}$ and shows namics in the second condition which are followed by declines. The dytions. When $\mathrm{N}$ is limiting, cell numbers response to limiting $\mathrm{N}$ concentrapool is recycled (set at 14 days) that it is again and it is only when the $\mathrm{N}$ growth. Notice at the beginning of each again available for phytoplankton accumulate during the winter month, year the $\mathrm{N}$ pool has ample time to nutrient limitation.

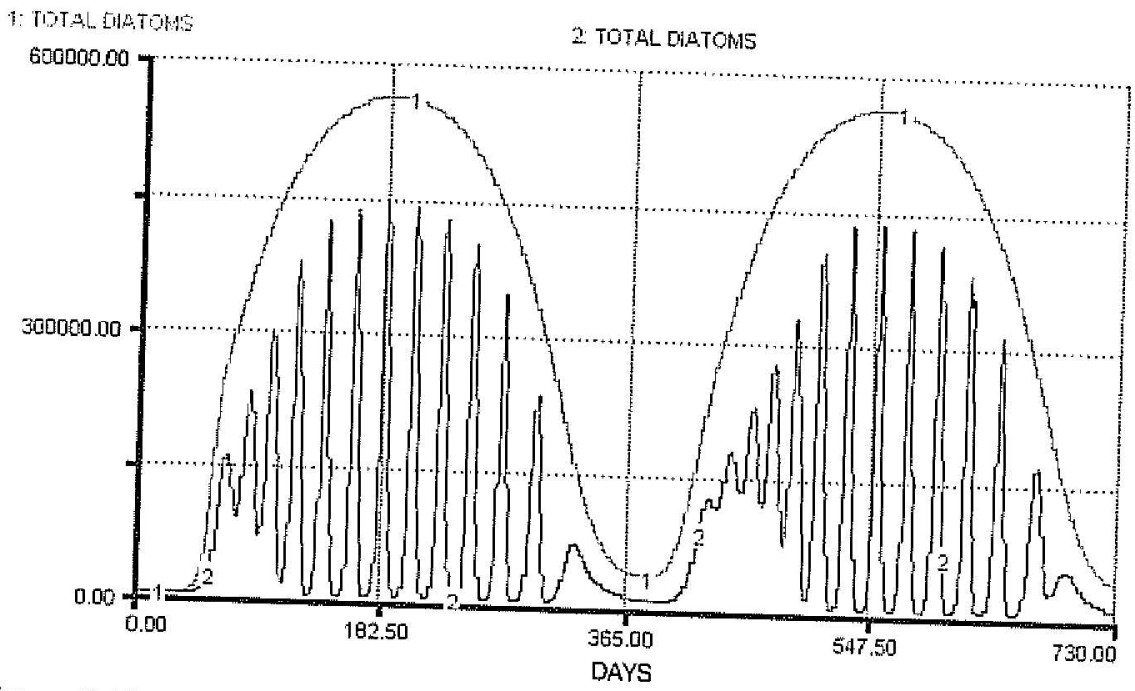

FiGure 8.13 
In addition to the $\mathrm{N}$ concentration affecting variability in the phytoplankton populations, changes the half-saturation constant $(\mathrm{Ks})$ regulate the ability of cells to take up nutrients. Higher $K s$ values require higher ambient nutrient concentrations to matntain maximum nutrient uptake rates. With $\mathbb{N}$ concentrations replete $\left(0.003\right.$ moles $\left./ \mathrm{m}^{3}\right)$, the $K s$ value of diatoms is increased. Figure 8.14 shows the ratio of diatoms to dinoflagellates equals 1 over the year when the $k$ s values are identical $\left(0.0005 \mathrm{moles} / \mathrm{m}^{3}\right)$ for both groups. As the $K s$ for diatoms is increased incrementally to $0.001 \mathrm{moles} / \mathrm{m}^{3}$ (run 4), the ability of dinoflagellates to utilize $\mathrm{N}$ is ligher than that of the diatoms and the dinoflagellate population dramatically increases relative to diatoms.

Until now, we have not considered the influence of a second nutrient on the two populations. If the $K s$ for Si uptake is set to $0.00005 \mathrm{moles} / \mathrm{m}^{3}$, diatom abundance is dependant on two nutrients, and dinoflagellate populations increase over time relative to diatoms (Figure 8.15). Unless both $N$ and $\mathrm{Si}$ are replete in the environment, the maximum growth rate for the diatoms cannot be realized. For diatoms, either $\mathrm{N}$ or Si will limit growth, depending on the physiological demand and the population size in the parcel of water. This demonstrates Liebig's "Law of the Minimum"-at any given time, if one nutrient is below the minimum requirement, the maximum growth potential of phytoplankton cannot be reached.

The model can be used to test responses in phytoplankton growth to varying $S i$ to $\mathrm{N}$ ratios. As a consequence, we can explore different scenarios, ranging from replete to limiting concentrations for both nutrients. Such exploration is particularly useful, for example, to illuminate implications of nutrient loading in a coastal ocean. Figure 8.16 shows the results of three

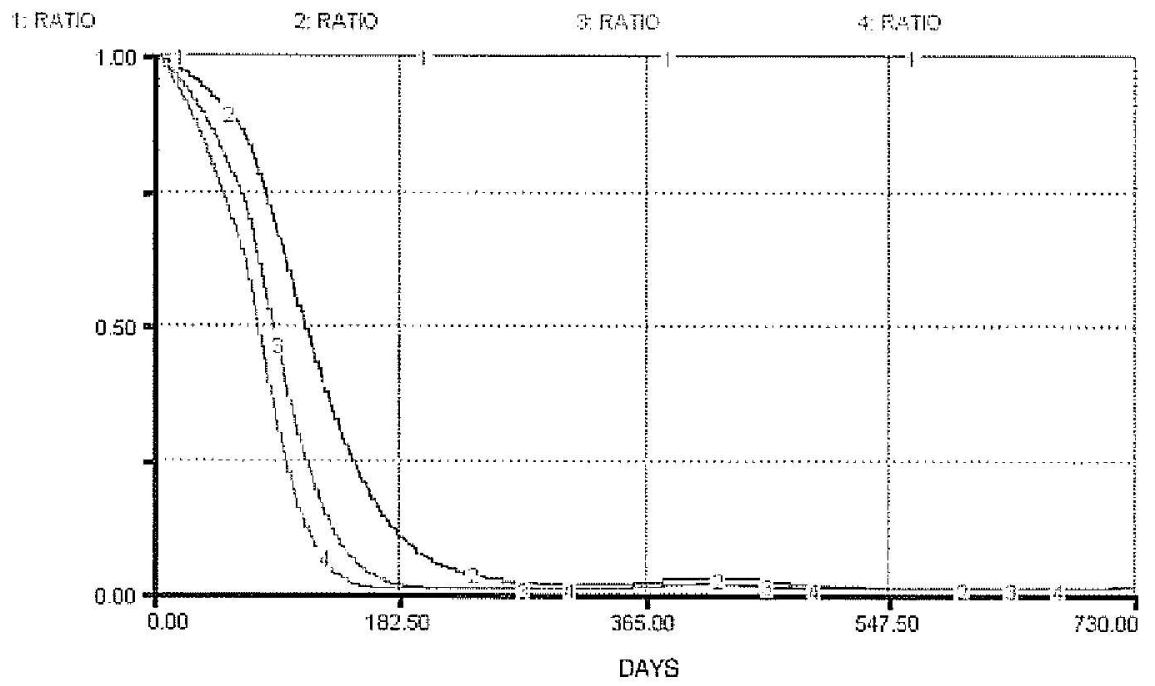

FIGURE 8.14 


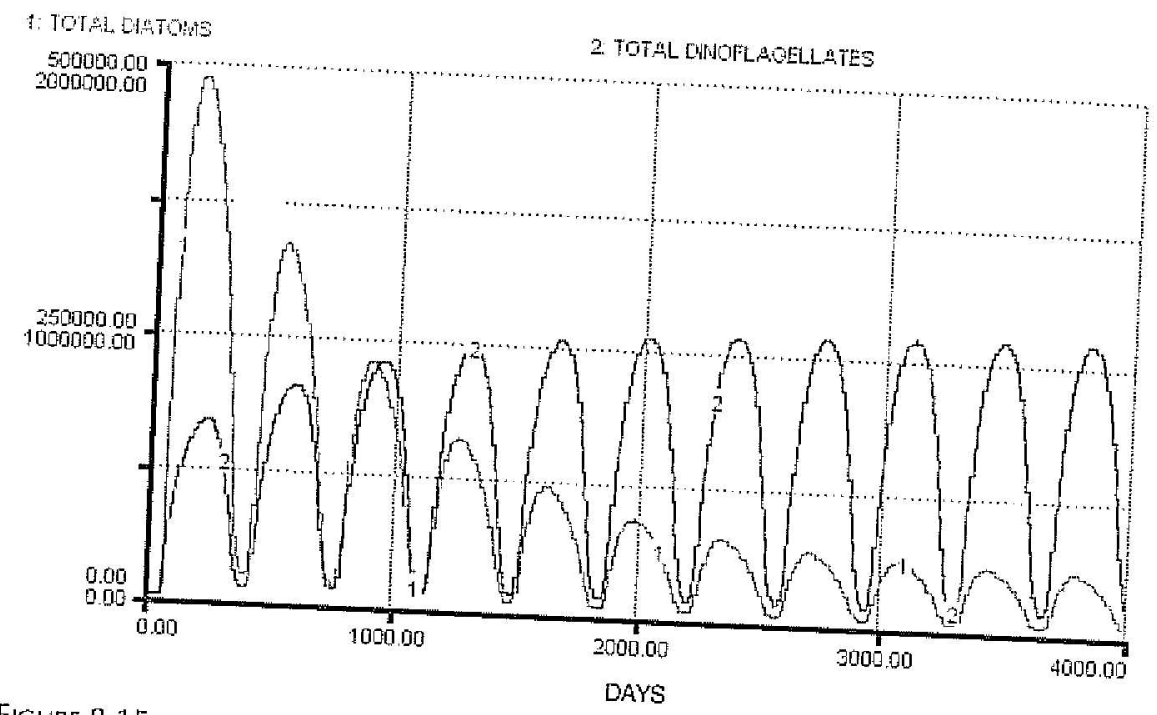

FiGiRe 8.15

sets of sensitivity runs for three $N$ concentrations spanning three orders of centration is varied $\left(0.001,0.003,0.008 \mathrm{~mol}^{3}\right)$. For each run, the Si con$\mathrm{Si}$ : N ratios from 0.033 to 26.67 . All 0.008 moles $/ \mathrm{m}^{3}$ ), producing a range of first set of runs (Graphs 1 through 3 ine runs are shown in Figure 8.16. The $\mathrm{Si}$, shows the ratio of diatongh 3 in Figure 8.16 ), with $0.001 \mathrm{moles} / \mathrm{m}^{3}$ of

1-9. FAт10

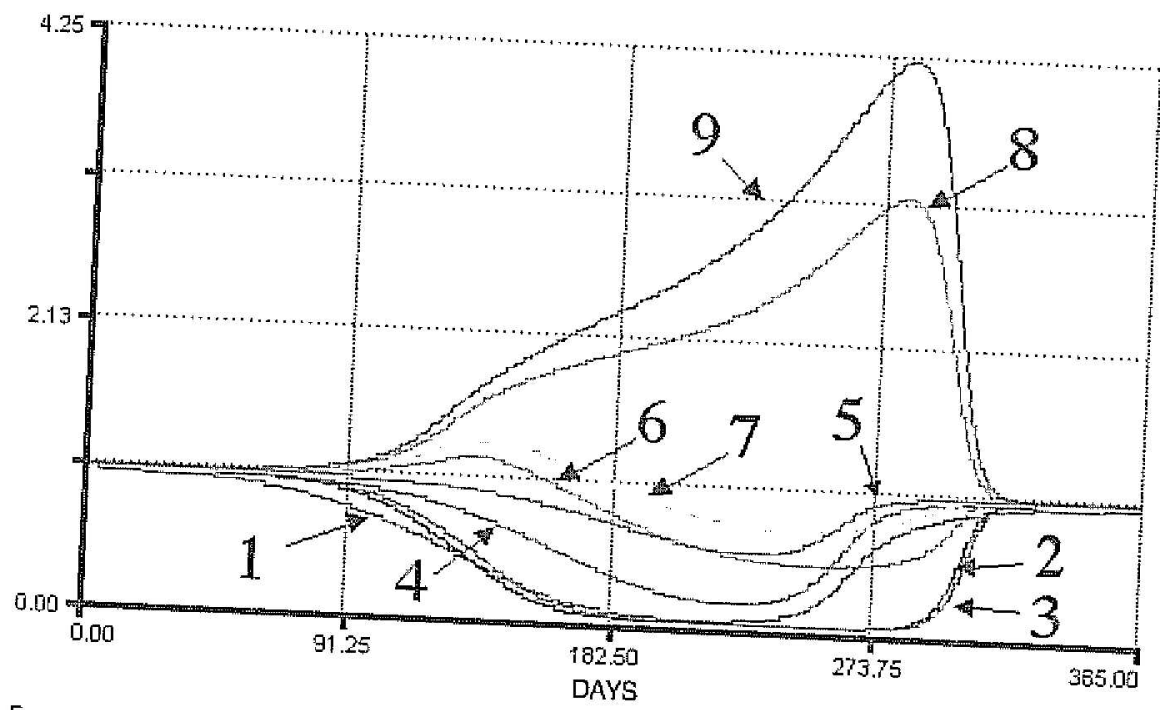

FIGURE 8.16 
higher concentrations of $\mathrm{N}$, the population of dinoflagellates increases. This is despite setting the growth rate higher for diatoms (1.05). This result is essentially being found in the Balic Sea and coastal regions (Elmgren 1989). Si concentrations have been shown to either remain the same, or to decrease, with the amount of $N$ loading increasing, thereby changing the ratio of nutrients and selecting against siliceous phytoplankton such as diatoms. With Si concentrations higher $\left(0.003\right.$ or $\left.0.008 \mathrm{moles} / \mathrm{m}^{3}\right)$, there is ample Si to maintain maximal growth of diatoms and dominate over the year.

\subsection{Conclusions}

This model illustrates the use of STELLA in describing a competitive biological interaction between two phytoplankton species. Although simple in its approach, the model incorporates some of the complexities inherent to the processes resulting in phytoplankton growth, such as physical mixing and the responses to in water light fields. As with any modeling exercise, it was important in this model to begin the model formulation with a simple and basic interaction, then build in the complexity. The center of the model is the response of growth to nutrients and the differential response of the individual groups to the two nutrients. Light is added and used to regulate the nutrient requirement for each species and light, in turn, is driven by the mixing dynamics.

The response of the model is similar to the competitive interactions in the marine environment, with one pinytoplankton group doninating when the nutrient required for growth is present. Although diatoms in this case have ample supplies of nitrate, if the nutrient concentration for silicate is not adequate for maximal growth, this moklel shows that dinoflagellates will always dominate. The increased occurrence and frequency of non-siliceous phytoplankton blooms, often dinoflagellates, have become a concern bectuse they are olten toxic and can increase mortality in fish, shellfish, birds, and marine mammals. Changes in phytoplankton communities in the coastal ocean will directly impact both the local coastal food webs and pelagic species that depend on coastal habitats for reproduction and/or seasonal feeding. From a larger ecological perspective, these model results, and the real changes that are occurring in coastal phytoplankton assemblages, illustrate the significance and far-reaching effects of nutrient runoff and coastal eutrophication.

\subsection{Questions and Tasks}

1. For the physical mixing part of the model, alter the parameters for mixing depth and period of mixing with time and look at the changing light dynamics. What is the mixing depth at which the populations are lightlimited for growth during mid-July on Julian day 197? 
2. Use the built-in PUILSE function to examine the effects of pulsed nutrichapter.

3. The model follows bhe at a time). How would you change the parcel of water (i.e. one depth integrated response (i.e. the entire the model to provide the depththese phytoplankton communities water column at a given time) of

4. The present model includes two phytoplantiton spes?

dinoflagellates-and two nutrients. phytoplankton species-diatoms and third nutrient to the model. How do the either a thircl competitor ar a

5. Explore ways to add phytoplankton grazes (zoop dynamics change?

where, for example, the grazer's feeding efficooplankton) to the model, ber of phytoplaniston cells, the size and/ficiency is based on the numdo the effects of changes in nutrient and/or type of phytoplankton. How plankton dynamics?

\section{PHYTOPLANKTON COMMUNITIES MODEL}

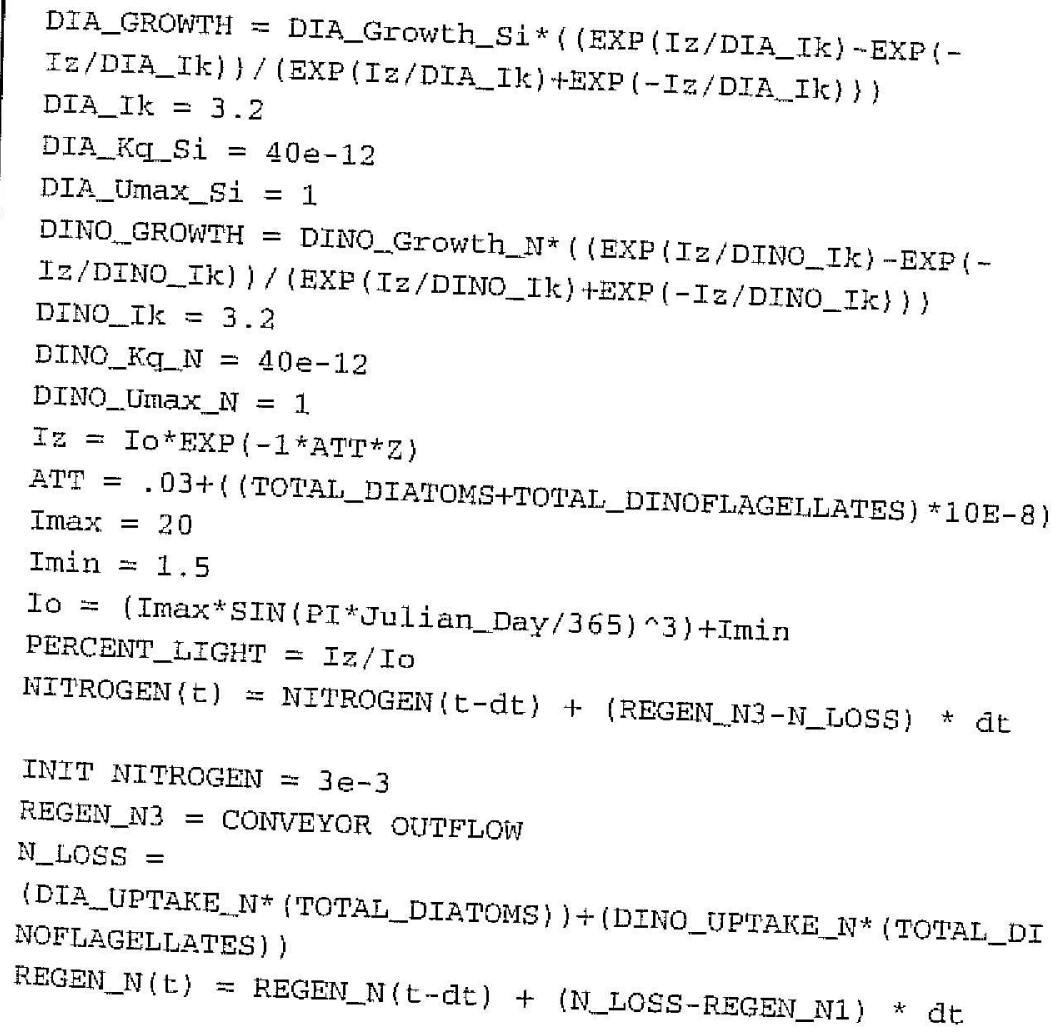




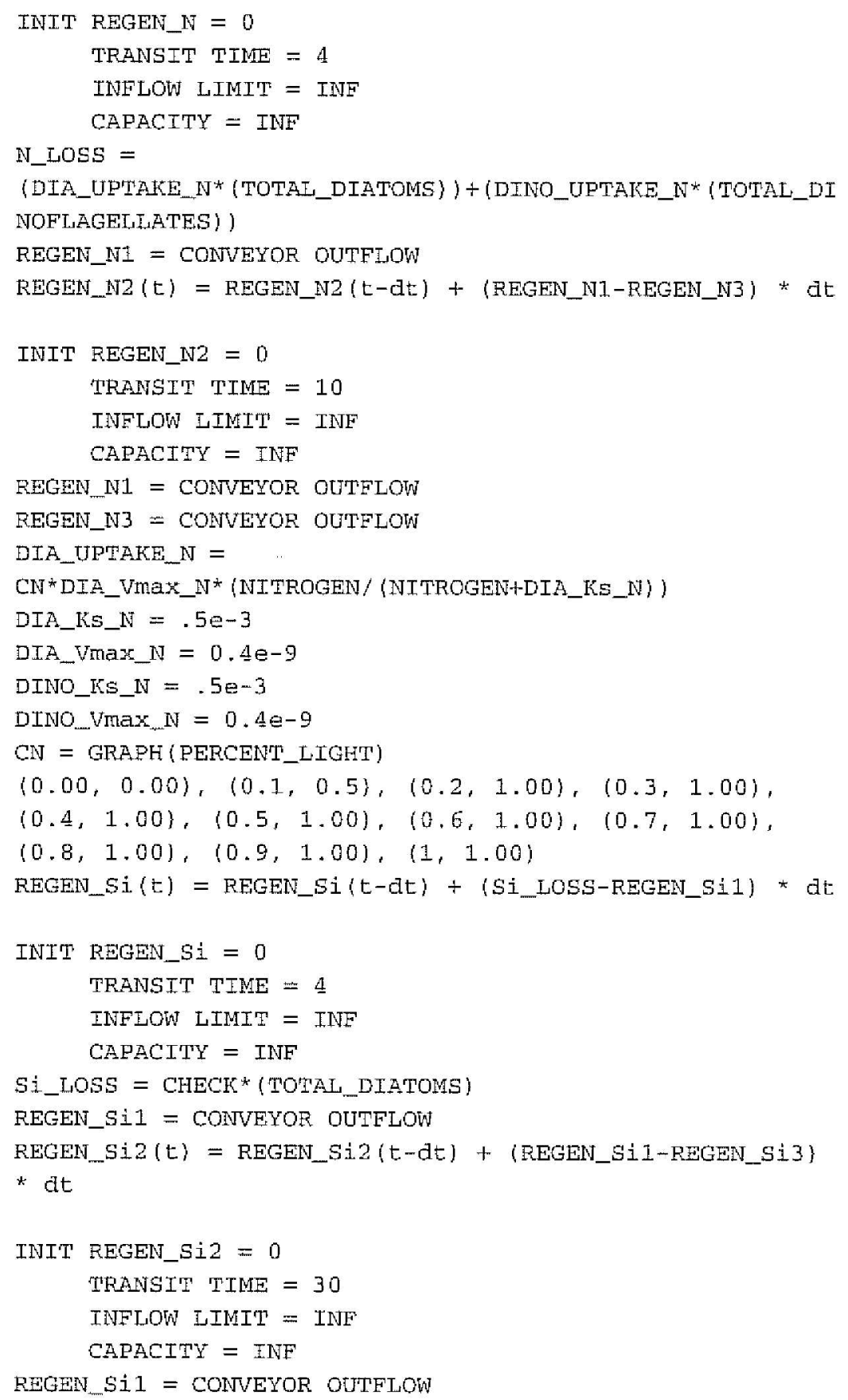




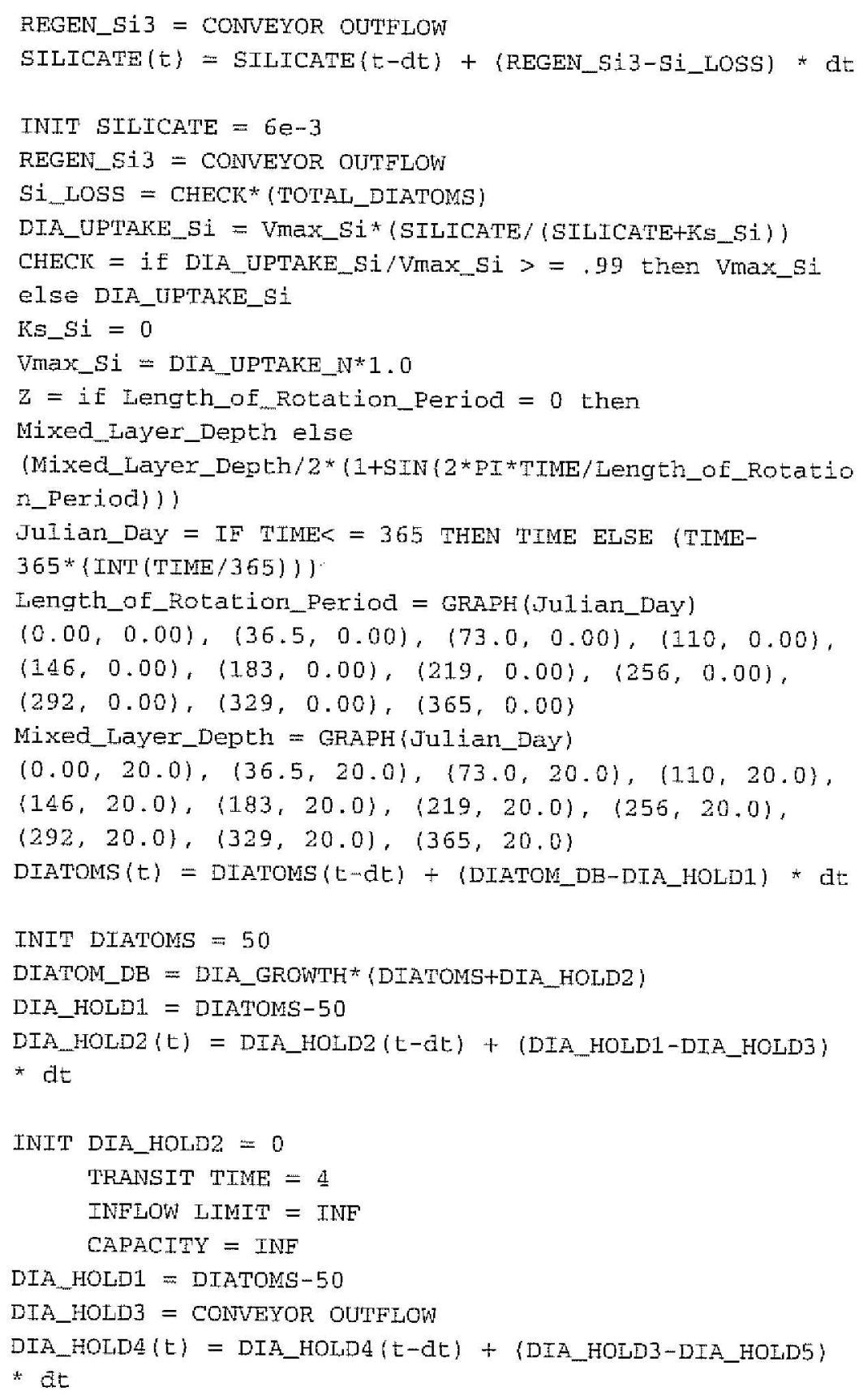




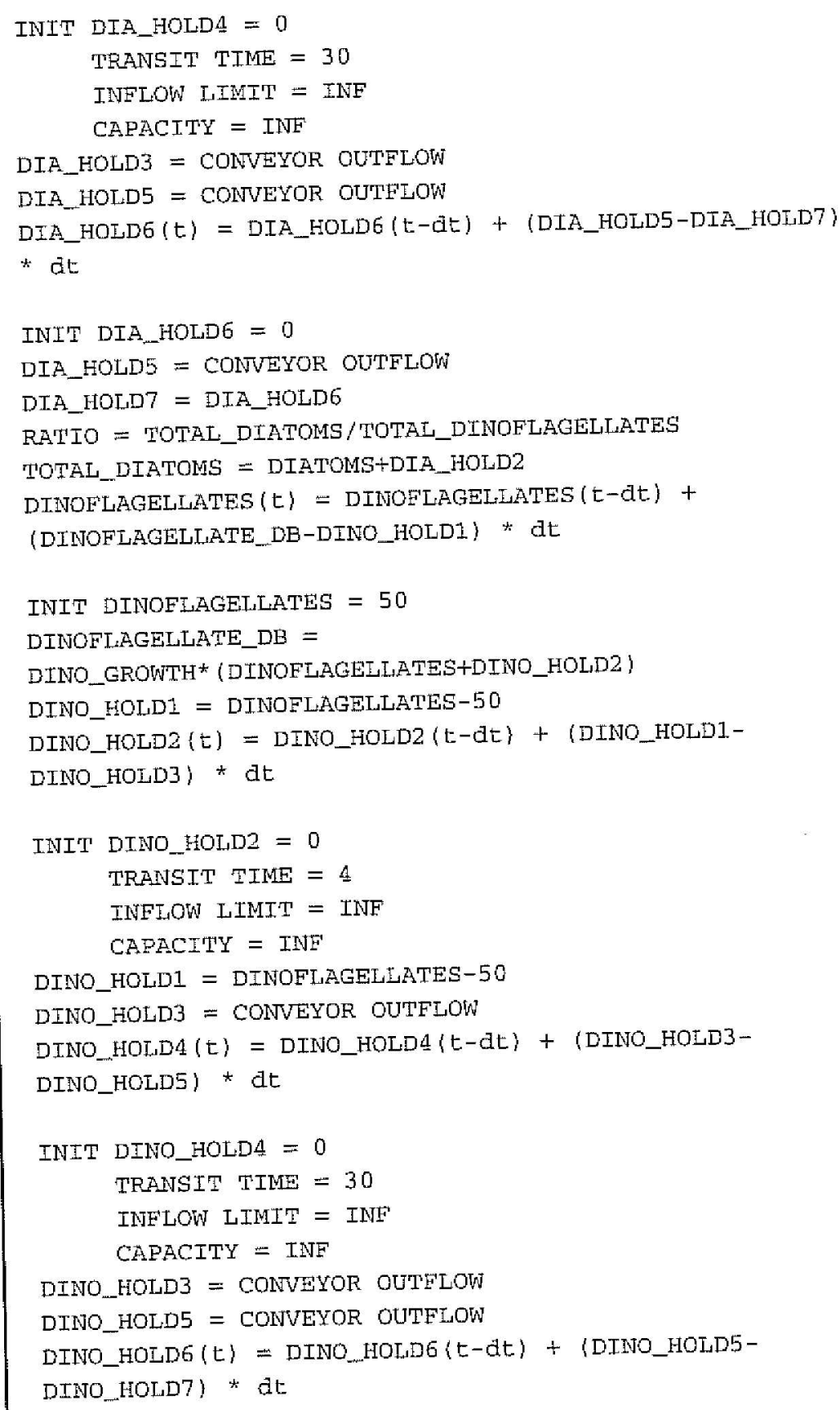


INIT DINO_HOLD6 $=0$

DTNO HOLD5 $=$ CONVEYOR OUTFLOW

DINO_HOLD7 = DTNO_HOLDE

TOTAL_DINOFLAGEILATES = DINOFLAGELLATES+DINO_HOLD2 